\title{
Association of Class I Dental Caries and Pulpectomy in Maxillary First Primary Molars Among Patients
}

\author{
Reshmi B ${ }^{1}$, Bhagya Lakshmi $T^{2 *}$ and Arvind $S^{3}$ \\ ${ }^{1}$ Saveetha Dental College and Hospitals, Saveetha Institute of Medical and Technical \\ Sciences, Saveetha University, 162, Poonamallee high road. Chennai, India \\ ${ }^{2}$ Department of Pediatric and Preventive Dentistry Saveetha Dental College and Hospitals, Saveetha Institute \\ of Medical and Technical Sciences, Saveetha University, 162, Poonamallee high road. Chennai, India \\ ${ }^{3}$ Department of Orthodontics Saveetha Dental College and Hospitals, Saveetha Institute of Medical \\ and Technical Sciences, Saveetha University, 162, Poonamallee high road. Chennai, India \\ Corresponding author email: bhagyalakshmit.sdc@saveetha.com
}

\begin{abstract}
A major goal in pediatric dentistry is preservation of the integrity of primary teeth and their supporting tissues until the physiological process of exfoliation takes place. Pulpectomy serves such a purpose using various materials and techniques to fill the canals of primary teeth. Dental caries is prevailing for all age groups and more found in kids due to their eating habits. They keep eating without giving time for the PH to be back to normal, to prevent a barrier for caries. It's important for the tooth to be treated from caries. The aim of the study was to assess the pulpectomy in maxillary 1st primary molar with class 1 Caries. A total of 201 patients from the OP of Saveetha Dental College Chennai were randomly selected. They were informed about the study and details like age, gender and, tooth involvement, were collected. They were segregated according to their age and gender and this data was transferred to excel sheets. The data was copied to SPSS software for statistical analysis and chi square test was performed. Age group of 4 to 6 had high incidence and frequency of pulpectomy and was done for male when compared to females. This study concludes that male children have undergone more pulp therapy treatment than female children and also children of both genders are more prone to caries that led to pulp therapy at a very young age.
\end{abstract}

KEY WORDS: CLASS 1 CARIES, MAXILLARY MOLARS, PRIMARY TEETH, PULPECTOMY.

\section{INTRODUCTION}

A major objective of modern dentistry for children is to maintain the integrity of the primary dentition until normal exfoliation, for the purpose of promoting function, aesthetics and phonetics. The treatment of severely infected primary teeth can be challenging and there are few options for treating such teeth. American Academy of Pediatric Dentistry (AAPD) defines pulpectomy as a procedure which involves removal of the roof of the pulp chamber in order to gain access to the root canals which are debrided, enlarged, disinfected and filled later with a resorbable material.

Biosc Biotech Res Comm P-ISSN: 0974-6455 E-ISSN: 2321-4007

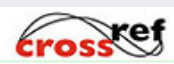

Identifiers and Pagination

Year: 2021 Vol: 14 No (10) Special Issue

Pages: 65-69

This is an open access article under Creative

Commons License Attribn 4.0 Intl (CC-BY).

DOI: http://dx.doi.org/10.21786/bbrc/14.10.11
Consequently, the tooth can be maintained in the arch without vital pulp tissue, but not compromising the function of the tooth. A high success rate of pulpectomy in primary teeth has led pediatric dentists to prefer pulpectomy over extraction and space maintainer (Christabel and Gurunathan, 2015; Somasundaram et al., 2015; Jeevanandan, 2017; Govindaraju et al., 2017).

Management of the grossly carious primary molar is a common but sometimes challenging aspect of dental care for young children. It is therefore essential that clinicians are both confident and competent in selecting and undertaking the most appropriate treatment for grossly carious primary molars. The aim of pulp therapy in a primary dentition is to retain every primary tooth as a fully functional component. To fulfil this major goal, vital pulp therapy through pulpectomy, is the most widely accepted technique for treating primary teeth with irreversible inflammation affecting the pulp chamber However, in cases of irreversibly inflamed and necrotic radicular canals, a successful pulpotomy cannot

\section{Article Information}

Received: $18^{\text {th }}$ Aug 2021

Accepted after revision: $25^{\text {th }}$ Oct 2021 
be achieved, and a partial or total pulpectomy is indicated (Trope and Bergenholtz, 2002; Parisav and Ghoddusi, 2015; Govindaraju et al., 2017; Ravikumar et al., 2017; Jeevanandan and Govindaraju, 2018; Panchal et al., 2019; Lakshmanan et al., 2020).

Pulpectomy is a conservative treatment approach to prevent the premature loss of primary teeth which can result in loss of arch length, in insufficient space for their erupting permanent teeth, tipping of molar teeth adjacent to the lost primary molar. In addition, pulpectomy is advantageous for retained primary molar teeth. Primary molar can be included in an interdisciplinary treatment approach, either by reducing the mesio distal width of the Crown or hemisection for orthodontic space management. Premature loss of the primary tooth may lead to accelerated or delayed eruption of the succedaneous tooth depending upon development of the permanent tooth. Because of high failure rate, pulp capping is not recommended for carious exposures in primary teeth. Other than mechanical exposure in a healthy tooth, all pulp exposures in primary teeth should be treated with pulpotomy, pulpectomy, or extraction. Thus, an appropriate pulpectomy of primary molar rather than extraction is a reasonable treatment option to ensure either the normal shedding pattern or longterm survival in instance of retention (Gesi et al., 2003; Aktan et al., 2012; Gurunathan and Shanmugaave 2016; Subramanyam et al., 2018; Mahesh, 2018; Lakshmanan et al., 2020).

By convention, any primary molar demonstrating a short duration of stimulus related pain with caries approximating the pulp is treated with vital pulp therapy. That is observed with symptoms including spontaneous pain, sinus tract, localised soft tissue inflammation, pathological mobility, radiographic evidence of abscess and resorption. When caries is confined to pulp, any treatment option should be addressed directly or indirectly. The purpose of study was done to find which molar is constantly being treated for pulpectomy and has been affected with caries (Oackiri, 2017; Govindaraju and Gurunathan, 2017).

\section{MATERIAL AND METHODS}

This was a retrospective study involved 201 patients with age between 1-10 years old visiting Saveetha Dental College and Hospital, Chennai from June 2019 till April 2020. Ethical approval was granted by the Institutional Ethics Committee of Saveetha Dental College. Data was collected based on the data availability from patients who underwent pulpectomy with class 1 Caries in the maxillary first left and right primary molars. All the data were based on clinical examination, photos and radiographic imaging in the system The inclusion criteria's Healthy co-operative children in the age group of 1-10 years, who had at least one primary tooth indicated for pulpectomy and exclusion criteria were patients who had systemic conditions. The internal validation includes randomisation including patients pulpectomy records. External validation includes cross verification of existing studies. The collected data was further segregated based on age, gender and added in excel sheets. The data added in excel sheets were transferred to SPSS software. Analysis like correlations, chi square tests were done to come to a detailed result analysis. They were further represented in graphs for better understanding.

\section{RESULTS AND DISCUSSION}

A total of 201 patients were seen during the study period. Male children were more commonly affected than females and the upper left first primary molar was highly prone for class 1 caries among our study population. Age group of 4-6 years had a high incidence of class 1 caries that led to pulp therapy. From figure 1 we can see that $54.2 \%$ of male and $45.7 \%$ of female children underwent pulp therapy for class 1 Caries in primary maxillary first molars. Figure 2 depicts $19.90 \%$ of the study population belonged to the age group of $1-3$ years, $45.7 \%$ belonged to the age group of $4-6$ and $34.3 .8 \%$ belonged to the age group of $7-10$ years. The age group between 4-6 yrs being the most vulnerable for class 1 Caries.

Figure 1: Figure shows the gender wise distribution of study population where female children (pink) were $45.7 \%$ and male children (dark blue) were $54.2 \%$. Male children were more than females

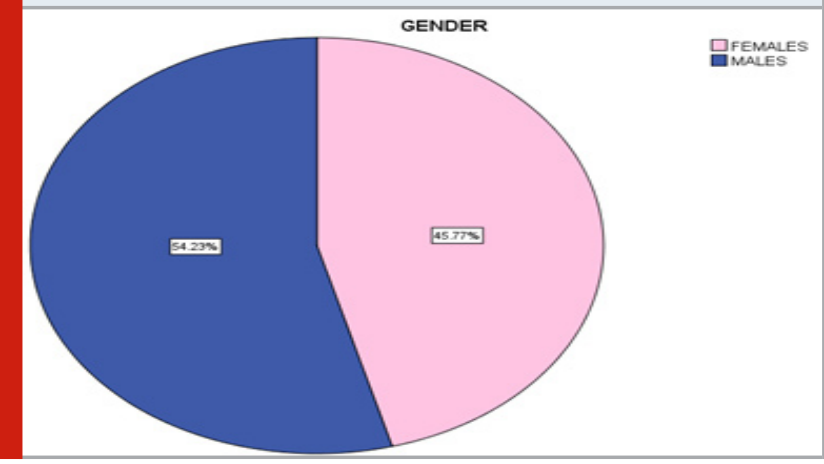

Figure 2: Figure shows the age wise distribution of study population where $19.9 \%$ belonged to the group of $1-3$ (light blue), $45.7 \%$ belonged to the age group of 4-6 (red) and $34.3 \%$ belonged to the age group 7-10 (green). It shows that children belonging to the age group of 4-6 were highly prevalent to class 1 Caries and underwent the highest pulpectomy procedure.

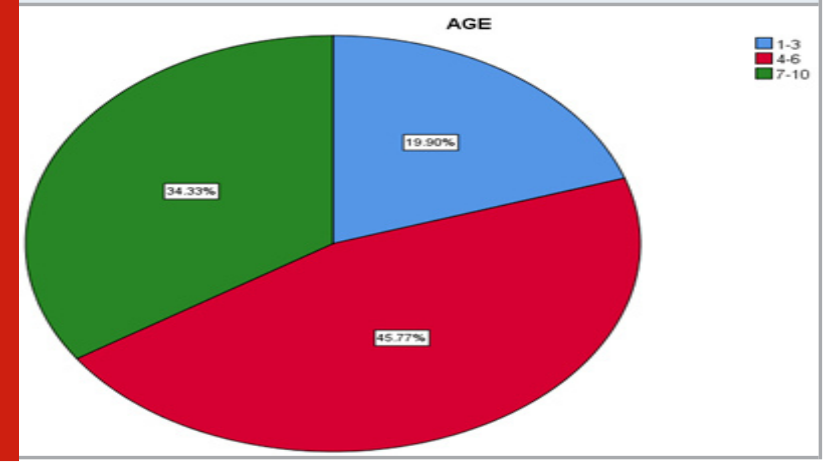

Figure 3 shows that $6.97 \%$ of females belonged to the age group of $1-3,21.89 \%$ of them belonged to the age group of 4-6 and $16.92 \%$ belonged to the age group of $7-10.12 .94 \%$ of males belonged to the age group of $1-3,23.88 \%$ of them 
belonged to the age group of 4-6 and $17.41 \%$ belonged to the age group of 7-10. Figure 4 reveals that class 1 caries occurred highly in the upper left primary molar with $27.6 \%$ of them belonging to the age group of 4-6 years and 17.9\% of population belonging to age 7-10. Figure 4 shows $p$ $=0.740(\mathrm{p}>0.05)$ which shows insignificant association between age and teeth involved. Figure 5 shows that $31.34 \%$ male children underwent pulp therapy in the left upper primary molar and $25.37 \%$ of the female children underwent pulp therapy for 64 . Figure 5 shows $p=0.736$ $(p>0.05)$ which shows insignificant association between teeth and gender.

Figure 3: Figure represents the association of age and gender. The $x$-axis represents the age of the children and Y-axis represents the percentage of the study population. Chi square was done and association was found to be statistically not significant. Chi square test value was 2.368 and $P=0.306$ $(\mathrm{P}>0.05)$, which is statistically not significant. From this graph we can infer that $23.88 \%$ of males (blue)belonging to the age group 4-6 were high followed by $21.89 \%$ of females (pink) of the same age group

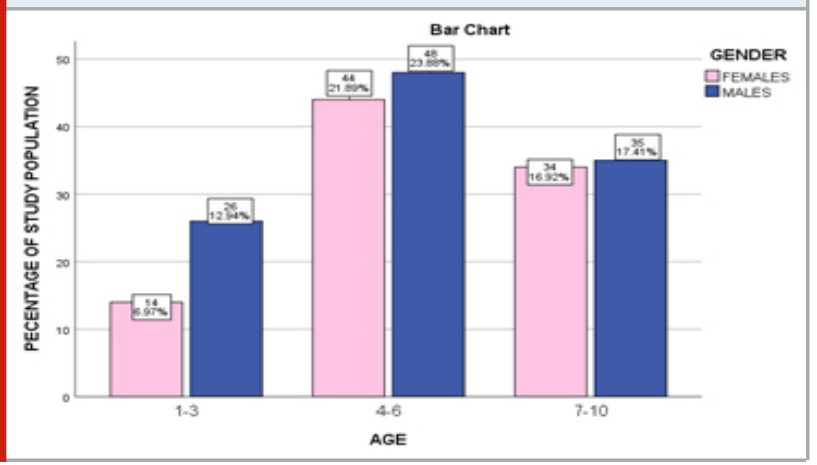

Figure 4: figure shows the association of teeth that underwent pulpectomy and age distribution. $\mathrm{X}$-axis represents the age of the patients and $\mathrm{Y}$-axis represents the number of pulpectomy treated teeth. Chi square test was done and association was found to be statistically insignificant. Chi square test value was 0.603 and $P=0.740(P>0.05)$, which is statistically not significant. Hence from the graph we infer that the 64- upper left primary maxillary molar $(\mathbf{2 7 . 8 6 \% )}$ is more affected in children belonging to the age group 4-6 years (Dark green).

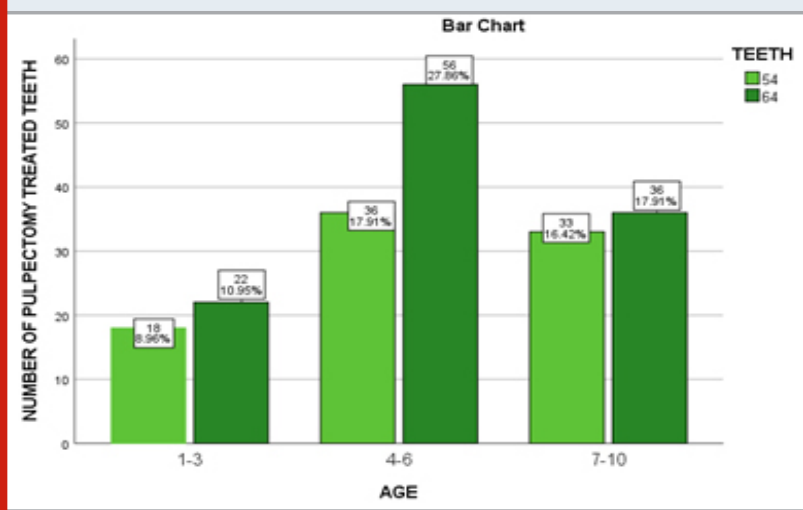

Figure 5: Figure shows the association of gender and teeth that underwent pulpectomy. $X$ - axis represents the gender and $\mathrm{Y}$-axis represents the number of pulpectomy treated teeth. Chi square test was done and association was found to be statistically insignificant. Chi square value was 0.114 and $P=0.736(P>0.05)$ which is statistically not significant. Hence from this figure we infer that male child had undergone the highest number of pulpectomy procedures $(31.3 \%)$ in upper left maxillary primary molars-64 (Dark green).

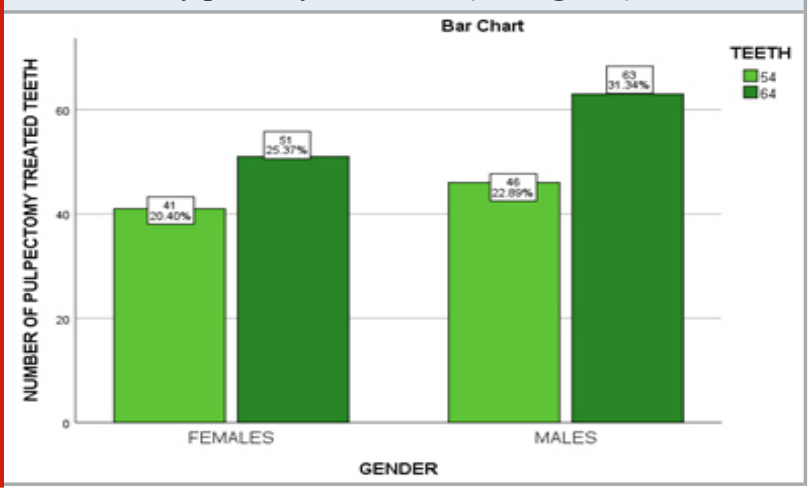

In this study, pulpectomy done in maxillary primary molars with class 1 caries were analysed and correlated with gender, age and tooth involved. All the pulpectomy cases with class 1 caries occurring in right and left upper first molars were segregated according to age and gender. In our study $54.2 \% \%$ of the male children were treated for pulpectomy and $45.8 \%$ were treated for pulpectomy. In a study by Santa Maria et al $82 \%$ of male children underwent pulpectomy and $15 \%$ of female children underwent pulpectomy. In a study, single visit endodontic treatment is carried out in $59.5 \%$ of pulpectomy cases, in our study all the cases included were multi visit ret. In another study $72.53 \%$ pulpectomy was done in cases with lesion and in our study all the cases (Velvart and Spoerry 1992; De-Souza et al., 2014; Santamaria et al., 2014; Panchal et al., 2019; Lakshmanan et al., 2020).

In this study $45.8 \%$ of females have undergone pulpectomy and $54.2 \%$ of the males underwent pulp therapy and, in a study, conducted in alaska $52.6 \%$ of the male children underwent pulp therapy and $47.4 \%$ of the female children underwent pulptherpay. In this study, the highest percentage of the age group was 4-6 years and left first primary molars were treated the maximum when compared to the right first primary molars for the same age group. The highest percentage was for the age group of 6-9 years. The total percentage of male children in this study population was $54.2 \%$ and female children was $45.8 \%$. Generally male children were more than female children in the total sample. The higher percentage was found for pulpectomy in the primary left first molar than the primary right first molar. The limitation of the study was that it was confined to one dental college in Chennai and including primary maxillary and mandibular second molars and would have given a brief knowledge (Rawson et al., 2019; Lakshmanan et al., 2020). 
This study reveals that the age groups of 4-6 years were more prone to class 1 Caries, Male and female children had a high incidence of class 1 Caries in maxillary left first primary molars. This study will help professionals to know the incidence of pulpectomy and can explain to parents to get them a clear idea about the importance of retaining the primary tooth. Regardless of the decision concerning the primary tooth and to the different treatment modalities, attention should be directed to the prognosis of the tooth in question, by restoring its health and function.

\section{ACKNOWLEDGEMENTS}

The authors are thankful to the Director of Saveetha Dental College and Hospital, Chennai.

\section{Conflicts of Interest: nil}

\section{REFERENCES}

Aktan AM, Kara I, Sener I, Bereket C, Celik S, Kirtay M, et al. (2012). An evaluation of factors associated with persistent primary teeth [Internet]. Vol. 34, The European Journal of Orthodontics. p. 208-12. Available from: http:// dx.doi.org/10.1093/ejo/cjq189

Christabel SL, Gurunathan D. (2015). Prevalence of type of frenal attachment and morphology of frenum in children, Chennai, Tamil Nadu. World J Dent. 6(4):6 (4)203-7.

de Souza Netto M, Saavedra F, Júnior JS, Machado R, Silva EJNL, Vansan LP. (2014). Endodontist's perceptions of single and multiple visit root canal treatment: a survey in Florianópolis--Brazil. RSBO Revista Sul-Brasileira de Odontologia. 11(1):14-9.

Gesi A, Bergenholtz G. (2003). Pulpectomy - studies on outcome. Vol. 5, Endodontic Topics. p. 57-70. Available from: http://dx.doi.org/10.1111/j.16011546.2003.00020.x

Govindaraju L, Gurunathan D. (2017). Effectiveness of Chewable Tooth Brush in Children-A Prospective Clinical Study. J Clin Diagn Res. 11(3): 31-4.

Govindaraju L, Jeevanandan G, Subramanian E. (2017). Clinical Evaluation of Quality of Obturation and Instrumentation Time using Two Modified Rotary File Systems with Manual Instrumentation in Primary Teeth. J Clin Diagn Res. 11(9): ZC55-8.

Govindaraju L, Jeevanandan G, Subramanian EMG. (2017). Comparison of quality of obturation and instrumentation time using hand files and two rotary file systems in primary molars: A single-blinded randomized controlled trial. Eur J Dent. 11(3):376-9.

Govindaraju L, Jeevanandan G, Subramanian EMG. (2017). Knowledge and practice of rotary instrumentation in primary teeth among indian dentists: A questionnaire survey. Vol. 9, Journal of International Oral Health. p. 45.
Available from: http://dx.doi.org/10.4103/jioh.jioh_4_17 Gurunathan D, Shanmugaavel AK. (2016). Dental neglect among children in Chennai. J Indian Soc Pedod Prev Dent. 34(4):364-9.

Jeevanandan G, Govindaraju L. (2018). Clinical comparison of Kedo-S paediatric rotary files vs manual instrumentation for root canal preparation in primary molars: a double blinded randomised clinical trial. Vol. 19, European Archives of Paediatric Dentistry. p. 273-8. Available from: http://dx.doi.org/10.1007/s40368-0180356-6

Jeevanandan G. Kedo-S Paediatric Rotary Files for Root Canal Preparation in Primary Teeth - Case Report. J Clin Diagn Res. (3): ZR03-5.

Lakshmanan L, Mani G, Jeevanandan G, Ravindran V, Subramanian EMG. (2020). Assessing the quality of obturation and instrumentation time using Kedo-S files, Reciprocating files and Hand K-files. Vol. 23, Brazilian Dental Science. 2020. Available from: http://dx.doi. org/10.14295/bds.2020.v23i1.1822.

Mahesh, R., MM (2018). Fluoride, Fluoridated Toothpaste Efficacy and Its Safety in Children-Review. International Journal of Pharmaceutical Research. doi, 10.

Packiri S. (2017). Management of Paediatric Oral Ranula: A Systematic Review. JOURNAL OF CLINICAL AND DIAGNOSTIC RESEARCH. Available from: http:// dx.doi.org/10.7860/jcdr/2017/28498.10622

Panchal V, Jeevanandan G, Subramanian E. (2019). Comparison of instrumentation time and obturation quality between hand K-file, H-files, and rotary Kedo-S in root canal treatment of primary teeth: A randomized controlled trial. J Indian Soc Pedod Prev Dent. 37(1):75-9.

Parisay I, Ghoddusi J, Forghani M. (2015). A review on vital pulp therapy in primary teeth. Iran Endod J. 10(1):6-15.

Ravikumar D, Jeevanandan G, Subramanian EMG. (2017). Evaluation of knowledge among general dentists in treatment of traumatic injuries in primary teeth: A crosssectional questionnaire study. Eur J Dent. 11(2):232-7.

Rawson TH, Rayes S, Strizich G, Salazar CR. (2019). Longitudinal Study Comparing Pulpectomy and Pulpotomy Treatments for Primary Molars of Alaska Native Children. Pediatr Dent. 15;41(3):214-20.

Santamaria RM, Innes NPT, Machiulskiene V, Evans DJP, Splieth CH. (2014). Caries Management Strategies for Primary Molars. Vol. 93, Journal of Dental Research. 2014. p. 1062-9. Available from: http://dx.doi. org/10.1177/0022034514550717

Somasundaram S, Ravi K, Rajapandian K, Gurunathan D. (2015). Fluoride Content of Bottled Drinking Water in Chennai, Tamilnadu. J Clin Diagn Res. 9(10): ZC32-4.

Subramanyam D, Gurunathan D, Gaayathri R, Vishnu 
Priya V. (2018). Comparative evaluation of salivary malondialdehyde levels as a marker of lipid peroxidation in early childhood caries. Eur J Dent. 12(1):67-70.

Trope M, Bergenholtz G. (2002). Microbiological basis for endodontic treatment: can a maximal outcome be achieved in one visit? Vol. 1, Endodontic Topics. 2002. p.
40-53. Available from: http://dx.doi.org/10.1034/j.16011546.2002.10104.x

Velvart P, Spoerry U. (1992). Pulpotomy versus incomplete pulpectomy as an endodontic emergency treatment. Vol. 18, Journal of Endodontics. 1992. p. 196. Available from: http://dx.doi.org/10.1016/s0099-2399(06)81470-6 